\title{
Research and Mechanism of Two-step Preparation of Acetamide from Microalgae under Hydrothermal Conditions
}

\author{
Jikang Jiang ${ }^{l}$, Haixia Ye ${ }^{2}$, Jingfei Zhou ${ }^{l}$, Chenlu Wang ${ }^{l}$, Zheng Shen ${ }^{l, 3,}$, and Yalei Zhang ${ }^{l, 3}$ \\ ${ }^{1}$ National Engineering Research Center of Protected Agriculture, Tongji University, Shanghai 200092, China \\ ${ }^{2}$ Shanghai Huajie Ecological Environment Engineering Co., Ltd., Shanghai, 201407, China \\ ${ }^{3}$ State Key Laboratory of Pollution Control and Resource Reuse, Tongji University, Shanghai 200092, China
}

\begin{abstract}
A two-step synthesis of acetamide under hydrothermal condition from microalgae, is presented. results showed that the best yield of acetamide and selectivity of acetic acid were $9.5 \%$ and $60.1 \%$ at $320{ }^{\circ} \mathrm{C}$ for 8 min with a NH3 supply of 30. Algae such as spirulina, cyanobacteria and autotrophic chlorella could also acquire acetamide, and lactic acid was found to be an important intermediate during the exploration of reaction pathways. These results demonstrated that it is possible to develop a process for conversion of microalgae biomass into acetamide.
\end{abstract}

\section{Introduction}

Diminishing fossil fuel reserves and ever-increasing $\mathrm{CO}_{2}$ (carbon dioxide) concentration have prompted the exploration for an alternate renewable and sustainable energy source [1]. Meanwhile, the treatment of algae mud caused by algae bloom has been the focus of research in recent years [1]. As a result, microalgae are thought to be a candidate for future fuel. Microalgae is indeed a promising feedstock for advanced biofuels production owing to many compelling reasons [2], such as faster growth rate [3,4], shorter multiplication cycle [5, 6], higher photosynthetic efficiency [3, 4] and maximum productivity $[5,6]$. Microalgae can also be cultivated in saline and alkaline land or wastewater, and it is a good way to preserve conventional cropland and remove nitrogen, phosphorus, and heavy metals in wastewater [2]. Microalgae has the excellent ability to capture $\mathrm{CO}_{2}$ for itself growth and finally can be converted into non-toxic and degradable biodiesel, which relieve environmental problems $[7,8]$.

There has been many researches committing to convert various biomass into biofuel and value-added chemicals $[1,8-10]$, and hydrothermal process is one of the most promising methods [11-14] because of its unique inherent properties when HTW (high-temperature water) behaves as reaction medium. HTW above the critical point undergoes drastic changes in its physical properties such as dielectric constant, density, ionic product, viscosity, and solubility [15]. Ionic product $\left(\mathrm{K}_{\mathrm{w}}\right)$ of HTW, about 1000 times higher than that of ambient liquid water [16], and the low dielectric constant, are both favourable to promote reactions without catalysts and have a good selectivity on the products $[12,14]$. HTW also haves the good transport property to mix small organic compounds completely and break down hydrocarbons and carbohydrates [17-19]. Most importantly, compared to other ways, the hydrothermal treatment of microalgae does not require dehydration, which could save a great deal of energy in the period of pretreatment $[1,19]$.

Acetic acid is one of main and stable intermediates during hydrothermal oxidation of organics [1], which contributes it to be the target product for organic waste utilization [20]. Acetamide is widely used in various industries and plays an important role in our daily life. For instance, acetamide is an excellent solute due to its higher dielectric constant, a promising PCMs (Phase-changematerial) for its good stability during thermal cycles [21] and a wetting agent. At the same time, Acetamide pesticides are important compounds of selective herbicides, can effectively control phytopathogenic fungi (peronosporales) in potatoes, sugar beets, and other crops [22].Besides, the traditional industrial method for acetamide is to make glacial acetic acid mixed with enough $\mathrm{NH}_{3}$, and pure acetamide is received through a series of pyrolysis, dehydration, crystallization, and separation process.

The two-step production of acetamide from microalgae under hydrothermal conditions seems to be a good way to utilize waste and satisfy the requirement of low carbon. A series of experiments to study the effects of reaction temperature, $\mathrm{NH}_{3}$ supply and reaction time on the acetamide production were performed, and possible reaction pathways were proposed.

\section{Experimental}

\subsection{Materials}

Hydrogen peroxide (GR, $\geq 30 \%$ ) used as $\mathrm{H}_{2} \mathrm{O}_{2}$ supply, ammonia (GR, 25-28 \%) used as $\mathrm{NH}_{3}$ apply, both convenient for handling, were supplied by Sinopharm 
Chemical Reagent Co., Ltd, China. The Spirulina, Cyanobacteria and Autotrophic chlorella were chosen to be the representative algae. The food grade Spirulina powder was obtained from Shandong BinzhouTianjian Biotechnology Co., Ltd., China. The powder was dried for $1 \mathrm{~h}$ at $105^{\circ} \mathrm{C}$ in a drying oven to eliminate error before each experiment; Cyanobacteria was the manufactured material of algae from Taihu Lake, which has been pretreated with a series of procedures such as cleaning, sedimentation, centrifugation, drying and trituration; Autotrophic chlorella was cultivated in SE medium. Table 1 lists the elemental composition of three kinds of microalgae analysed on a dry basis.

Table 1. Elemental analysis of representative algae.

\begin{tabular}{|c|c|c|c|c|c|}
\hline Category & $\begin{array}{c}\mathrm{C} \\
(\%)\end{array}$ & $\begin{array}{c}\mathrm{N} \\
(\%)\end{array}$ & $\begin{array}{c}\mathrm{H} \\
(\%)\end{array}$ & $\begin{array}{c}\mathrm{O} \\
(\%)\end{array}$ & $\begin{array}{c}100 \% \\
\mathrm{H}_{2} \mathrm{O}_{2} \\
\text { supply }\end{array}$ \\
\hline Spirulina & 46.84 & 8.37 & 6.96 & 37.83 & $0.71 \mathrm{ml}$ \\
\hline Cyanobacteria & 46.56 & 5.74 & 7.73 & 40 & $0.69 \mathrm{ml}$ \\
\hline $\begin{array}{c}\text { Autotrophic } \\
\text { chlorella }\end{array}$ & 36.18 & 7.33 & 5.36 & 48.14 & $0.50 \mathrm{ml}$ \\
\hline
\end{tabular}

\subsection{Definition of terms}

The definition of terms is shown as follows. Yield of acetic acid ( $\mathrm{mol} \%)$ :

$$
Y=\frac{\text { Moles of carbon in lacetic acid produced }}{\text { Moles of carbon in loaded microalgae sample }}
$$

Yield of acetamide ( $\mathrm{mol} \%)$ :

$Y=\frac{\text { Moles of carbon in acetamide produced }}{\text { Moles of carbon in loaded microalgae sample }}$ $\times 100 \%$

Selectivity of acetic acid (mol\%):

$Y=\frac{\text { Moles of acetamide produced in step } 2}{\text { Moles of lacetic acid produced in step } 1} \times 100 \%$

$100 \% \mathrm{H}_{2} \mathrm{O}_{2}$ supply was defined as the volume of hydrogen peroxide (provide $30 \% \mathrm{wt} \quad \mathrm{H}_{2} \mathrm{O}_{2}$ ) used to completely oxidize microalgae, where microalgae (approximated by $\mathrm{C}_{3.90} \mathrm{H}_{6.96} \mathrm{~N}_{0.60} \mathrm{O}_{2.36}$ ) was converted to carbon dioxide, nitric acid and water, assuming $1 \mathrm{~mol}$ of $\mathrm{H}_{2} \mathrm{O}_{2}$ gives $1 / 2 \mathrm{~mol}$ of $\mathrm{O}_{2}$ [23].

$$
\mathrm{C}_{3.90} \mathrm{H}_{6.96} \mathrm{~N}_{0.60} \mathrm{O}_{2.36}+10.42 \mathrm{H}_{2} \mathrm{O}_{2} \rightarrow 3.90 \mathrm{CO}_{2}+0.60 \mathrm{HNO}_{3}+13.60 \mathrm{H}_{2} \mathrm{O}
$$

Correspondingly, $100 \% \mathrm{NH}_{3}$ supply was defined as the volume of ammonia (provide $26 \% \mathrm{wt} \mathrm{NH}_{3}$ ) used to convert acetic acid produced in the first step into acetamide totally.

$$
\mathrm{CH}_{3} \mathrm{COOH}+\mathrm{NH}_{3} \cdot \mathrm{H}_{2} \mathrm{O} \rightarrow \mathrm{CH}_{3} \mathrm{CONH}_{2}+2 \mathrm{H}_{2} \mathrm{O}
$$

\subsection{Experimental procedure}

The schematic drawing of the experimental set-up can be found elsewhere [1, 23-27]. 1) In a typical hydrothermal experiment, $0.067 \mathrm{~g}$ microalgae and 0.3-1.1 $\mathrm{mL}$ hydrogen peroxide were loaded into a batch-type reactor, which was made of stainless steel SUS316 tube (3/8-inch diameter, 1-mm wall thickness, 120-mm length) with two-end fittings, providing an inner volume of $5.7 \mathrm{~mL}$. 2) The reactor was immersed into a salt bath preheated to a desired temperature and kept shaking horizontally. 3) After the reaction, the reactor was placed into a cold-water bath to quench the reaction. 4) For the second-step reaction, the reactor was opened quickly and added into $0.3 \sim 0.98 \mathrm{~mL}$ ammonia immediately after cooling to room temperature and finally sealed again. 5) Repeat the abovementioned procedures 2) and 3), samples of the liquid phase in the reactor were filtrated with a $0.45 \mu \mathrm{m}$ filter and collected into the sample bottles for the subsequent detection. All the second-steps were directly conducted on optimal reaction conditions and yields of acetic acid respectively from representative algae based on previous research (Table 2). So, we took Spirulina powder as the key object and referred it as microalgae due to a higher yield of acetic acid among these representative algae. In all experiments, a loading of a mixture of deionized water, hydrogen peroxide and ammonia was usually set at $30 \%$, namely $1.7 \mathrm{~mL}$. The reaction time was defined as the time that the reactor was kept in the salt bath, and the actual reaction time was shorter than the apparent reaction time.

Table 2. Optimal reaction conditions and yields of acetic acid of representative algae.

\begin{tabular}{|c|c|c|c|c|}
\hline Category & $\begin{array}{c}\text { Temperature } \\
\left({ }^{\circ} \mathrm{C}\right)\end{array}$ & $\begin{array}{c}\mathrm{H}_{2} \mathrm{O}_{2} \\
\text { supply } \\
(\%)\end{array}$ & $\begin{array}{c}\text { Time } \\
(\mathrm{S})\end{array}$ & $\begin{array}{c}\text { Yields } \\
(\%)\end{array}$ \\
\hline Spirulina & 300 & 100 & 80 & 14.9 \\
\hline Cyanobacteria & 300 & 160 & 60 & 12.1 \\
\hline $\begin{array}{c}\text { Autotrophic } \\
\text { chlorella }\end{array}$ & 320 & 160 & 100 & 12.0 \\
\hline
\end{tabular}

\section{Results and discussion}

\subsection{Preliminary experiments}

To verify the feasibility of the study, the preliminary experiments were carried on at $80 \mathrm{~s}, 300{ }^{\circ} \mathrm{C}$ and $0.067 \mathrm{~g}$ $\left(\mathrm{NH}_{4}\right)_{2} \mathrm{CO}_{3}$ with first-step products of Spirulina. The pretreated samples were analysed by HPLC, and the results were shown as Fig.1. It was evident that acetamide was formed after the second-step reaction due to the peak.

Next, to explore whether there were other substances produced during the second-step reaction, we compared the products of the acetic acid sample and ammonia at $300^{\circ}$ $\mathrm{C}$ and $500 \% \mathrm{NH}_{3}$ supply for 1 minute and 2 minutes. In Fig.2, the total moles of acetic acid and acetamide were equal to the initial concentration of acetic acid sample $(6800 \mathrm{mg} / \mathrm{L}$, the probable amount of acetic acid generated in the first step) in control group 1 and 2. Results indicated when put $\mathrm{NH}_{3}$ into acetic acid, we can stably produce acetamide as the only product. Therefore, acetamide could be regarded as the target product. 


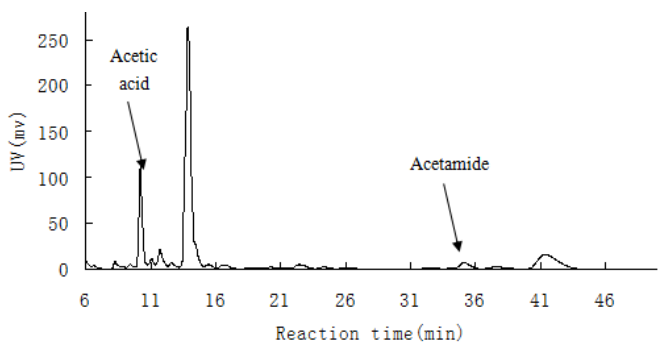

Fig. 1. HPLC of chlorella hydrothermal reaction products.

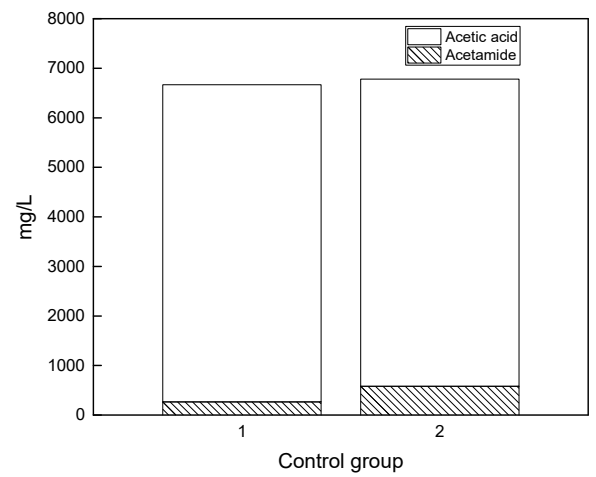

Fig. 2. Reactions of acetic acid sample and ammonia (UV detector Wavelength: $210 \mathrm{~nm}$, Column temperature: $80{ }^{\circ} \mathrm{C}$, Mobile phase: $1 \mathrm{mM} \mathrm{HClO} 4)$.

\subsection{Influence of reaction temperature on acetamide yields}

To examine the effects of reaction temperature on yields of acetamide from microalgae, a series of experiments were performed with a $\mathrm{NH}_{3}$ supply of 20 and reaction time for $8 \mathrm{~min}$ in the second step. Fig.3 showed the effects of reaction temperature on yields of acetamide in the twostep process between $250-350{ }^{\circ} \mathrm{C}$. The increase on temperature from $250{ }^{\circ} \mathrm{C}$ to $320{ }^{\circ} \mathrm{C}$ resulted in a monotonous increase on acetic acid selectivity from $21.1 \%$ to $53.5 \%$, acetamide yields from $3.2 \%$ to $8.1 \%$ respectively, indicating that acetic acid produced in the first step failed to react completely with newly supplied $\mathrm{NH}_{3}$. With temperature rising, yields of the acetamide boosted correspondingly. However, there was a slight negative effect on the production of acetamide when the temperature exceeded $320^{\circ} \mathrm{C}$. As the figure shown, the selectivity of acetic acid and yield of acetamide declined to $48.2 \%$ and $7.3 \%$ due to decomposition of production at this point. Therefore, it should be more suitable to take $320^{\circ} \mathrm{C}$ as reaction temperature in the two-step process.

\subsection{Influence of $\mathrm{NH}_{3}$ supply on acetamide yields}

Excess $\mathrm{NH}_{3}$ was required because ammonia could volatilize easily. Subsequently, experiments on effects of $\mathrm{NH}_{3}$ supply were conducted with $320^{\circ} \mathrm{C}, 8 \mathrm{~min}$ and a $\mathrm{NH}_{3}$ supply of 10 35 in the second step. The influence of $\mathrm{NH}_{3}$ supply on yields of acetamide in the two-step process was shown in Fig.4. In the beginning, the selectivity of acetic acid and yield of acetamide was only $41.6 \%$ and $6.3 \%$ when the $\mathrm{NH}_{3}$ supply was 10 folds. As $\mathrm{NH}_{3}$ supply increased, yields grew continuously and especially when the $\mathrm{NH}_{3}$ supply was 30 folds, the selectivity and yield obtained $60.1 \%$ and $9.1 \%$ as a maximum value. However, more $\mathrm{NH}_{3}$ supply did not result in an increase of the yields since then, indicating that reactions had reached a state of saturation. Furthermore, when $\mathrm{NH}_{3}$ supply was 10 folds, there was still a smell of ammonia after reaction according to the experimental phenomenon, showing that $\mathrm{NH}_{3}$ supply remained substantial. So, the recycling of $\mathrm{NH}_{3}$ should be considered when it comes to application in industry.

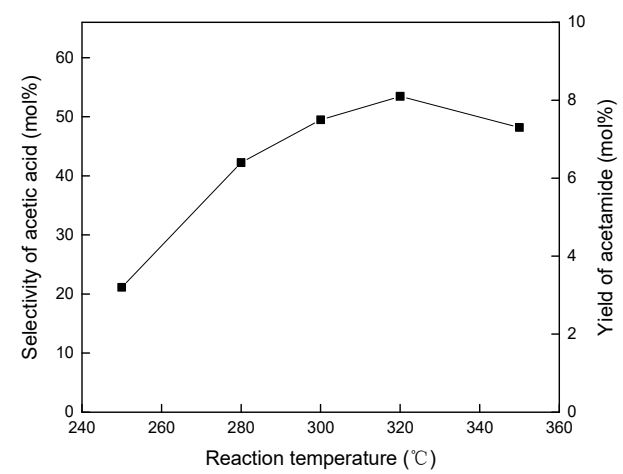

Fig.3. Effects of reaction temperature on selectivity and yield in the two-step process (step 1: $0.067 \mathrm{~g}$ microalgae; $100 \% \mathrm{H} 2 \mathrm{O} 2$ supply; $300{ }^{\circ} \mathrm{C}$; $80 \mathrm{~s}$; step 2: 20 folds NH3 supply; 8 min).

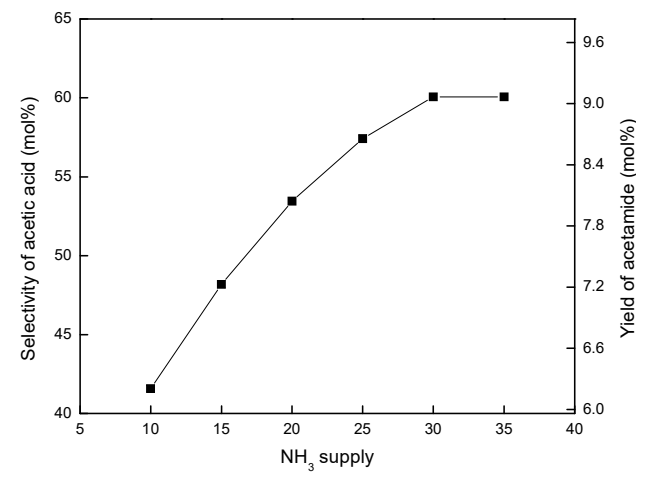

Fig.4. Effects of NH3 supply on selectivity and yield in the two-step process (step 1: $0.067 \mathrm{~g}$ microalgae; $100 \% \mathrm{H} 2 \mathrm{O} 2$ supply; $300{ }^{\circ} \mathrm{C} ; 80 \mathrm{~s}$; step $2: 320{ }^{\circ} \mathrm{C} ; 8 \mathrm{~min}$ ).

\subsection{Effect of reaction time on acetamide yields}

The effect of reaction time on yields of acetamide from microalgae was investigated under conditions of 20 folds $\mathrm{NH}_{3}$ supply, $320^{\circ} \mathrm{C}$ and 5-15 min. As illustrated in Fig.5, the yields of acetamide monotonously increased with the reaction time, and the selectivity and yield reached $60.1 \%$ and $9.1 \%$ after $8 \mathrm{~min}$. However, yields decreased slightly when the reaction time was up to $10 \mathrm{~min}$ and then began smooth gradually. It could be seen from that, acetamide was relatively steady or the speed of decomposition was equivalent to that of composition at the temperature of $320^{\circ} \mathrm{C}$. In the same way, the selection of $8 \mathrm{~min}$ as reaction time should be more desirable on yields of acetamide in the two-step process. 


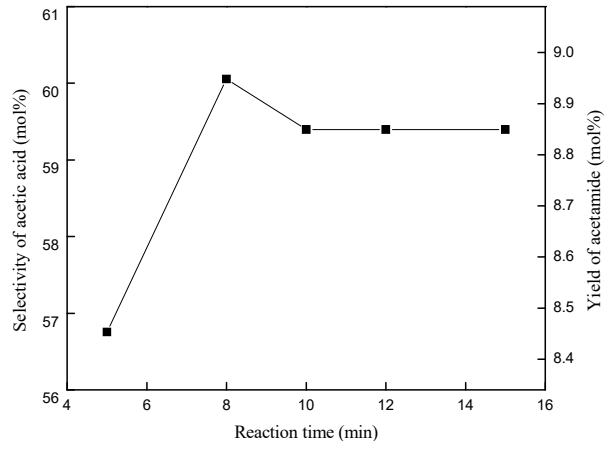

Fig.5. Effects of reaction time on selectivity and yield in the two-step process (step 1: $0.067 \mathrm{~g}$ microalgae; $100 \% \mathrm{H} 2 \mathrm{O} 2$ supply; $300{ }^{\circ} \mathrm{C}$; $80 \mathrm{~s}$; step 2: 20 folds $\mathrm{NH} 3$ supply; $320{ }^{\circ} \mathrm{C}$ ).

The effect of reaction time on yields of acetamide from microalgae was investigated under conditions of 20 folds $\mathrm{NH} 3$ supply, $320{ }^{\circ} \mathrm{C}$ and 5-15 min. As illustrated in Fig.5, the yields of acetamide monotonously increased with the reaction time, and the selectivity and yield reached $60.1 \%$ and $9.1 \%$ after $8 \mathrm{~min}$. However, yields decreased slightly when the reaction time was up to $10 \mathrm{~min}$ and then began smooth gradually. It could be seen from that, acetamide was relatively steady or the speed of decomposition was equivalent to that of composition at the temperature of $320^{\circ} \mathrm{C}$. In the same way, the selection of $8 \mathrm{~min}$ as reaction time should be more desirable on yields of acetamide in the two-step process.

\subsection{Possible pathway}

The yield of acetic acid from cellulose was only $6.3 \%$ based on related literatures, while yields were 12-14.9\% from three kinds of representative algae in this research. Compared to composition analysis of cellulose, high protein content in microalgae may be the main reason. Besides, according to protein-derived amino acids could be converted into acetic acid under hydrothermal conditions, basic amino acids were regarded as the objects and were conducted the following research. A sequence of reaction conditions was discussed, and alanine and aspartic acid, the two common amino acids, were considered as the main targets due to the higher yields of acetic acid. The optimum conditions were presented in Table 3.

Table 3. Optimal reaction conditions and yields of alanine and aspartic acid.

\begin{tabular}{|c|c|c|c|c|}
\hline Category & Temperature & $\mathrm{H}_{2} \mathrm{O}_{2}$ supply & Time & Yields \\
\hline alanine & $300{ }^{\circ} \mathrm{C}$ & $70 \%$ & $80 \mathrm{~S}$ & $36.9 \%$ \\
\hline $\begin{array}{c}\text { aspartic } \\
\text { acid }\end{array}$ & $320{ }^{\circ} \mathrm{C}$ & $160 \%$ & $80 \mathrm{~S}$ & $16.5 \%$ \\
\hline
\end{tabular}

There was a big difference between the yields of alanine and aspartic acid, $36.9 \%$ and $16.5 \%$ respectively from Table 4, probably because three-carbon alanine could proceed a simpler oxidative decomposition than four-carbon aspartic acid. HPLC and GC-MS analyses were used to identify acetic acid, propionic acid, acetamide and formic acid as the major products, and they could be explained by the proposed reaction mechanism in Fig.6 and Fig.7. In the first step, alanine undergoes a deamination reaction to lactic acid under hydrothermal conditions. And next, lactic acid will be oxidized to plenty of acetic acid, some propionic acid and trace formic acid in the presence of $\mathrm{H}_{2} \mathrm{O}_{2}$. Finally, some of acetic acid can be transformed to acetamide with $\mathrm{NH}_{3}$, which stems from the deamination reaction of alanine in the first step. While aspartic acid will proceed a more complicate decomposition and produce a variety of organic acids, such as alanine, malic acid, and lactic acid. On one hand, aspartic acid could afford alanine via a decarboxylation process, and the subsequent pathway is identical to the Fig.6. On the other hand, aspartic acid can also be converted into malic acid through a deamination reaction under hydrothermal conditions. There exits the tautomerism between malic acid and oxaloacetic acid, and the latter can be decarboxylated into pyruvic acid, eventually into formic acid. Similarly, formic acid decomposed by malic acid can be converted into formamide with $\mathrm{NH}_{3}$.

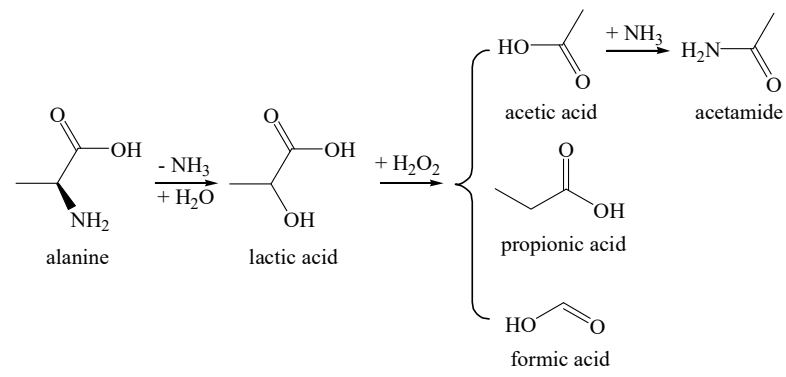

Fig.6. The possible pathway of alanine under hydrothermal conditions.

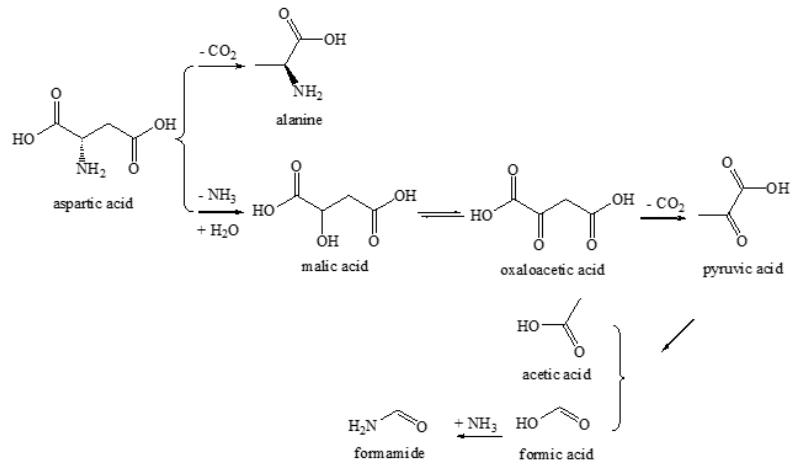

Fig.7. The possible pathway of aspartic acid under hydrothermal conditions.

So, the reason for lower yield in aspartic acid is that aspartic acid can undergo more reaction pathways and afford more products. More importantly, the pathways for aspartic are inclined to formic acid, because much formic acid was detected in the product of aspartic acid while no formic acid produced in alanine. During the production of acetic acid from microalgae, lactic acid is an important intermediate product and it can be converted into acetic acid under this hydrothermal condition. so how to improve the yield of lactic acid is crucial to the amount of acetic acid, and then acetamide. 


\section{Conclusion}

In conclusion, a two-step production of acetamide from three kinds of representative algae under hydrothermal conditions was discussed. Results showed that the best yield of acetamide and selectivity of acetic acid were $9.5 \%$ and $60.1 \%$ at $320{ }^{\circ} \mathrm{C}$ for 8 min with a $\mathrm{NH}_{3}$ supply of 30 from Spirulina, $8.0 \%$ and $66.9 \%$ at $320{ }^{\circ} \mathrm{C}$ for 8 min with a $\mathrm{NH}_{3}$ supply of 40 from Cyanobacteria, $8.1 \%$ and $67.5 \%$ at $320{ }^{\circ} \mathrm{C}$ for 8 min with a $\mathrm{NH}_{3}$ supply of $40 \mathrm{NH}_{3}$ supply from Autotrophic chlorella respectively. The results not only provide a green and sustainable process to produce acetamide from microalgae, but also facilitate the utilization of microalgae biomass. On the other hand, based on the reaction pathway of alanine and aspartic acid, lactic acid is an important intermediate during the twostep production of acetamide from microalgae under hydrothermal conditions. So, increasing the yield of lactic acid is the key to improve the amount of acetic acid and acetamide.

\section{Acknowledgements}

This work was Supported by Lab of Green Platemaking and Standardization for Flexographic Printing (No. ZBKT201902).

\section{References}

1. Z. Shen, J. F. Zhou, X. F. Zhou ,Y. L. Zhang, Appl Energ 88, 3444-3447 (2011)

2. J. Yang, Q. He ,L. Yang, Appl Energ 250, 926-945 (2019)

3. C. Miao, O. Marin-Flores, T. Dong, D. Gao, Y. Wang, M. Garcia-Pérez ,S. Chen, ACS SUSTAIN CHEM ENG 6, 4521-4530 (2018)

4. C. Rösch, M. Roßmann, S. Weickert, GCB Bioenergy 11, 326-334 (2019)

5. G. Vicente, A. Carrero, R. Rodríguez ,G. L. del Peso, Fuel 200, 590-598 (2017)

6. N. Pragya, K. K. Pandey ,P. K. Sahoo, RENEW SUST ENERG REV24, 159-171 (2013)

7. M. Packer, Energy Policy 37, 3428-3437 (2009)

8. D. R. Vardon, B. K. Sharma, J. Scott, G. Yu, Z. Wang, L. Schideman, Y. Zhang, T. J. Strathmann, Bioresour Technol 102, 8295-303 (2011)

9. J. Miller, L. Evans, A. Littlewolf ,D. Trudell, FUEL, 1363-1366 (1999)

10. J. Remón, J. Randall, V. L. Budarin ,J. H. Clark, GREEN CHEM 21, 284-299 (2019)

11. Wahyudiono, M. Sasaki ,M. Goto, CHEM ENG PROCESS 47,1609-1619 (2008)

12. F. Jin ,H. Enomoto, Energy Environ. Sci. 4, 382-397 (2011)

13. J. Remón, T. Li, C. J. Chuck, A. S. Matharu ,J. H. Clark, ACS SUSTAIN CHEM ENG 7, 16160-16172 (2019)

14. G. Yin, F. Jin, G. Yao ,Z. Jing, IND ENG CHEM RES 54, 68-75 (2015)
15. R. Shaw, CHEM ENG NEWS 69, 26-39 (1991)

16. W. L. Marshall, E. U. Franck, J PHYS CHEM REF DATA 10, 295-304 (1981)

17. S. Ghoreishi, T. Barth ,D. H. Hermundsgard, ACS Omega 4, 19265-19278 (2019)

18. R. Samiee-Zafarghandi, A. Hadi ,J. Karimi-Sabet, BIOMASS BIOENERG 121, 13-21 (2019)

19. P. J. Valdez, M. C. Nelson, H. Y. Wang, X. N. Lin ,P. E. Savage, BIOMASS BIOENERG 46, 317-331 (2012)

20. L. Yu, X. Zhuang, L. Bai, F. Li, W. He, G. Li ,J. Huang, J CLEAN PROD 113,925-930 (2016)

21. S. S. Magendran, F. S. A. Khan, N. M. Mubarak, M. Vaka, R. Walvekar, M. Khalid, E. C. Abdullah, S. Nizamuddin ,R. R. Karri, Nano-Structures \& NanoObjects 20, (2019)

22. H. Buser, M. Muller, T. Poiger ,M. Balmer, ENVIRON SCI TECHNOL,221-226 (2002)

23. F. Jin, Kishita, T. Moriya ,H. Enomoto, J SUPERCRIT FLUID, 251-262 (2001)

24. Y.-1. Zhang, M. Zhang, Z. Shen, J.-f. Zhou, X.-f. Zhou, J CHEM TECHNOL BIOT 88, 829-833 (2013)

25. Z. Shen, M. Gu, M. Zhang, W. Sang, X. Zhou, Y. Zhang, F. Jin, RSC Adv. 4, 15256-15263 (2014)

26. F. Jin, Z. Zhou, T. Moriya, H. Kishida, H. Higashijima ,H. Enomoto, ENVIRON SCI TECHNOL 39, 1893-1902 (2005)

27. F. Jin, A. Kishita, T. Moriya, H. Enomoto ,N. Sato, CHEM LETT 31, 88-89 (2002) 